\title{
Mac Wellman and the Language Poets: Chaos Writing and the General Economy of Language
}

\section{Keith Appler}

Shake the flour can, get the particles.

You lift the rod one inch too far, and the core's crazy, you're plastered on account of the ceiling.

-Mac Wellman's Cellophane

By the time Marjorie Perloff would write the foreword to the 2001 Cellophane: Plays by Mac Wellman, she would note that, in addition to Bertolt Brecht, Samuel Beckett, Sam Shepard, and Harold Pinter, Mac Wellman also "recalls . . . the language poets-Bruce Andrews, Charles Bernstein, Steve McCaffery-who are his contemporaries." Wellman, a prolific experimental playwright, has corresponded with Bernstein at least since $1977,{ }^{2}$ and among Wellman's extensive bicoastal associates is the Language poet Douglas Messerli, founder of Sun and Moon Press of Los Angeles. Wellman, described as a "language" writer by New York Times reviewer Mel Gussow in $1990,{ }^{3}$ is identified as a Language poet in 2008 by Helen Shaw in her foreword to Wellman's third major play collection. Shaw writes that Wellman "has been the deconstructionists' mountaintop; he has read the very choppy tablets given down by the Black Mountain gang and the Language Poets (he is one). But he also returns to us [in the theatre] with their message." "Shaw's identification of Wellman as a Language poet in no way diminishes his importance in the theatre, although his first plays were radio plays adapted from his poetry, and his dramatic works, always off-beat, suggest his "poetical" preoccupation with producing unconventional and emphatically non-didactic effects through linguistic and theatrical means. His plays have appeared in New York and on the West Coast since the late 1970s, when he was quickly successful in winning grants and awards for his plays, as well as forming important theatre relationships. The one with En Garde Arts director Anne Hamburger led to the site-specific plays Crowbar, at the Victory Theatre on Broadway, and Bad Penny at Bow Bridge, in Central Park. Wellman and composer David Lang collaborated on The Difficulty of Crossing a Field. Collections of Wellman's plays have been published by major

Keith Appler teaches at the University of Macau and writes on plays and institutionality in the 1980s and 1990s. 
academic presses, among them Johns Hopkins University Press and University of Minnesota Press. His prominence as a playwright rose in the mid- to late 1980s with bicoastal productions and important notice in the New York Times and in American Theatre magazine, and publication in Yale's Theater journal of his first manifesto ("The Theatre of Good Intentions") attacking middlebrow theatre. The study which follows focuses on two of three plays associated with an experiment in "bad writing," Cellophane and Terminal Hip, that stand apart in Wellman's always-experimental drama as his most sustained use of nonsense to produce non-meaningful effects. Less will be said about Three Americanisms, the third play in the bad-writing series, which takes a new direction. However, all three of these plays demonstrate Wellman's strong affinity with Language poetry, which emerges most clearly in them just as deconstruction and chaos theory are becoming conversant with one another.

While the Language poets, who emerged in the late 1970s, are a heterogeneous group, ${ }^{5}$ they have tended to be politically progressive, theory-driven, and modernist in their self-definition. This modernism registers in Charles Bernstein's 1992 declaration that " $[w]$ e can act: we are not trapped in the postmodern condition if we are willing to differentiate between works of art that suggest new ways of conceiving our present world and those that seek rather to debunk any possibilities of meaning. ${ }^{.6}$ At the same time, the Language poets eschew binary and linear thinking, and have absorbed deconstruction in their poetry and their theories.

By way of a notion of the deconstructive "general economy" of language, Bernstein and McCaffery agree that forms of expression (letters, words, images, sounds, gestures-language in its materiality) are of a completely different order from the institutions (contents of expression) in which they are situated or the official narratives (forms of content) with which their writing is engaged. These ideas derive from Georges Bataille and also from the Copenhagen linguist Louis Hjelmslev. ${ }^{7}$ Bernstein and McCaffery agree that meaning elides the materiality of expression to "refer to" (or to produce the look of) a stable order of reality and that in the postmodern, as power's meaningful repetitions (or reifications) have saturated everyday life, they must resist power by reasserting the materiality of expression. Unless poetry resists reproducing the "natural" correspondence of expression with content, it would be, like ideologically complicit academic verse, ${ }^{8}$ part of the problem. Bernstein's goal is, he writes, "to throw a wedge into this engineered process of social derealization." The Language poet's goal for cognition and understanding has been, George Hartley explained in 1989, "baring the frame" of the "production of meaning through the syntactical organization of force." ${ }^{10}$

Wellman is equally committed to asserting the materiality of expression in 
its spoken, written, and theatrical forms. He wrote in 1984 that "[a]rtists and thinkers of our time are engaged in a war against . . . the tyrannical domination of meanings so fixed, so absolute, as to render the means of meaning, which is to say the heart and soul of meaning, a mere phantom." ${ }^{11}$ Wellman, Bernstein, and McCaffery all have resisted the institutions of their genres while producing, as a kind of surplus value, a powerful affect that can be simultaneously alienating and absorbing for readers and spectators, at least for those who are not merely alienated by the strangeness of some of their work. In ordinary life, affect is an unformed feeling that lasts for half a second: it takes a half second for a stimulus response to form affect into an emotion and a direction within the frames of perception and meaning. ${ }^{12}$ One effect of Language writing is to extend that half second for the duration of the performance. The Language writer achieves this when his or her forms of expression keep the spectator at the border between meaning and nonsense. In ways that I will develop below, this is the border where meanings that leap into view are overwhelmed by meanings and nonmeaning in the next instant. This is the border between meaning, formed as a restrictive economy and lost in an instant, and the general economy of language.

The relationship between the general economy as a flow of language expression is staged in this model as a relationship of nonrelation with a restrictive economy, which constrains that flow of expression according to the contents of expression, understood as expressive modes and conduits that conform to forms of content, understood as the ideological order. Meaning expresses that ideological order and, as expression, recedes into the background as language refers itself to objects in the world. However, a practice that exploits the gap between expression and the ideological order to foreground the nonrelation of expression to this order is one that returns expression to the general economy and leaves the spectator at its threshold in an affective state of intensity.

The affective state of intensity can be apprehended, as I will show in comparing two of Wellman's plays, Cellophane and Terminal Hip, to Language poetry. But beyond describing the state itself we enter immediately into a host of problems accounting for the connections, if any, among authorial intentions, audience response, and critical interpretation. My purpose here is to explain the production of the affective state, but it is also to engage, if tentatively, with the theories that inspire these uses of language. With the Language poets, Wellman among them, this requires elaborating some important theoretical linkages. Wellman's embrace, in the early 1990s, of chaos theory is compatible with the deconstructive language practices so far described, if we are to understand the singular enunciation as a convergence of different systems (forms of expression, contents of expression, and forms of content) in relations of nonrelation. The convergence of these systems forms a complex interaction of constraints, producing new potential for variation within a more complex system. Theoretically this convergence of constraints and 
potentials, in the singular enunciation, produces unpredictable effects, potentially at different scales. N. Katherine Hayles writes that deconstruction and chaos theory, deriving as they do from the same episteme, had come, by the early 1990s, into productive conversation with one another. ${ }^{13}$ It is no surprise then that Wellman, a fellow traveler of the Language poets, should make his "chaos theory turn" at this moment, especially as he was, like Tom Stoppard, under the influence of James Gleick's 1988 book Chaos: Making a New Science. ${ }^{14}$ Hayles's point about the cultural importance of chaos at the time had to do with its appropriation, by cultural critics and artists, as a new way of conceiving and deconstructing the edifices of power. For artists and critics (if not for scientists), the ideas associated with chaos theory gave new credibility to nonrational and nonlinear ways of conceiving the world. ${ }^{15}$

William W. Demastes, writing of the "theatre of chaos," remarks that "chaos as a paradigm is revolutionary because it asks us to see the world from a different metaphorical stance. It is the metaphor that hits the mark in ways others to varying degrees have not. In fact, often chaos is quite literal and not metaphorical at all." ${ }^{16}$ But here I will say that in drama, it is not the metaphorical chaos allegories like Stoppard's Arcadia and Wellman's Cat's Paw, but Wellman's chaotic, nonmetaphorically effective plays Cellophane and Terminal Hip that, owing to the interplay of expressions and contents, present the chaotic phenomena upon which chaotic Language writing is to be theorized. Theoretically, our route through the Language poets is the straightest route from Wellman's language practice, consisting in the production of affective intensity, to an understanding of the relevance of his invocations of chaos theory.

\section{The Radioactivity of Language}

There is, of course, no escaping meaning, and even cognate lexemes are "radioactive" with meanings, including connotations, which carry their emotional charge. In discussions of poetic nonsense in the last decade many have begun, as does Perloff, with reference to Gertrude Stein, for whom "nonsense" is not the absence of meaning, but the frustration of a total system in which some meanings are advanced and others repressed. Perloff writes, "But words, as even Gertrude Stein recognized, have meanings, and the only way to MAKE IT NEW is not to pretend that meaning doesn't exist but to take words out of their usual contexts and create new relationships among them." 17 When the Language poet James Sherry complains that poetry's "old forms are radioactive with the halflives that constructed them," "18 or when, in a similar vein (referring to Bernstein's "business poems"), Perloff writes that "the pieces of the puzzle are always already contaminated, bearing, as they do, the traces of the media discourses . . . in which they are embedded," 19 "radioactivity" is understood as the toxicity of words, official discourses, and outmoded forms. One cannot detoxify language; one can, 
however, exploit this toxic radioactivity by raising its kinetic level. Although Bernstein is no ideologue, he understands ideology as highly useful for producing what he would consider nonideological effects: he writes that "[i]deology . . . everywhere informs poetry and imparts to it, at its most resonant, a density of materialized social being expressed through the music of the work as well as its multifoliate references." The connotations-investments and repudiationssurrounding culturally and/or politically freighted buzz words and scare words carry their histories with them: they are radioactive with those histories and lend their intensities to the musical flow of language. That Bernstein values mostly the intensification of fragmentary ideological reference is registered in his statement about the poetry scene of the early 1990s: "[t] he state of American poetry can be characterized by the sharp ideological disagreements that lacerate our communal field of action, making it volatile, dynamic, engaging. ${ }^{20}$

For Wellman, ideological meaning is also, in itself, "worthless, as are the foundations of knowledge." ${ }^{21}$ In the early 1980s, Wellman appears to have understood reification in its larger ideological forms even as he filled his plays with small breaks in the flow of the action, including non sequiturs and other surprises. Ideology was associated in these earlier plays with characters whose modes of thought, owing to the reifications in society, were not fully engaged with reality. Wellman himself explains that his 1983 Bad Infinity was the conclusion of a fiveplay series (including Energumen, Diseases of the Well-Dressed, The Professional Frenchman, and The Self-Begotten $)^{22}$ in which he was interested in contemporary "logic," 23 and we see that this final play features a more or less static Chekhovian lineup of "thinkers": the affectless (postmodern) artist John Sleight; the messianic Megan; the sentimental bourgeois murderer Ramon; Deborah, a spirit of negation; and Sam, the anarchosocialist (modernist) artist. A countersign to this postmodern disengagement from history was the philosopher Hegel. In Wellman's plays of the early 1980s, the Hegelian dialectic (dialectics in its "nonideological" form) does not operate well, owing to the reifications Bernstein and others have identified. If in Hegelian terms "spirit" must engage with history as necessity in order to transcend itself in a new synthesis, then history must be available in some more concrete way. Wellman, describing his work as "affective fantasy," blames "a refusal to accept any kind of dialectic in the workings of society" for "the strange malaise in our playwriting." ${ }^{24}$ This is an aspect of a simulacral condition Wellman thematizes as the Hegelian "bad infinity" where, owing to postmodern reifications, spirit (desire, creativity) can get no traction in its nonencounter with history (or necessity): the synthesis of the dialectical process does not take place. ${ }^{25}$ Or, more in keeping with Bernstein, ${ }^{26}$ Wellman's dialectic may correspond more fully with Theodor Adorno's negative dialectics. According to Adorno, a "successful work . . . is not one which resolves objective contradictions in a spurious harmony, but one which expresses the idea of harmony negatively by embodying the contradictions, 
pure and uncompromised, in its innermost structure. ${ }^{27}$ In this case, while there is no escape from the bad infinity of the modern world, art may, through means of embodiment that eschew meaning, offer a more vital engagement with the bad infinity of postmodern reification. Hartley writes that "[i]t is the achievement of many Language poets to think beyond the stalemate of the paradigmatic question [of meaning and ideology] and to pose poetry as an exploration of the syntagmatic. ... The role of poetry thus shifts from denying to revealing, unveiling, discovery."${ }^{928}$ It is their achievement, that is, to exploit the radioactivity of language, which, for Hartley, is to engage "dialectically" with the individual sign and sequence of signs to produce from these a "negative" but ultimately affirmative complexity.

Extending his concern with dialectics into the writing of work more like Language poetry itself, Wellman took up, a year later in 1984, his experiment in "bad writing," which carried on for over two years ${ }^{29}$ alongside the writing and production of plays like Dracula (1987) and Whirligig (1988). The bad-writing experiment resulted in Cellophane and Terminal Hip, and a later third play, Three Americanisms, which is the only one of the three indebted to Gleick's book. The bad-writing plays, essentially Language poems, are the clearest connection between Wellman's art and that of the Language poets. In ways I will develop, they are the most chaotic of his plays, so much so that only the most provisional interpretations may be offered by one always fearful of "[b]ark[ing] up the wrong tree. ${ }^{30}$ For example, provisional interpretation might suggest that the combination, across the field of writing from which Cellophane and Terminal Hip derive, of the Eliotic wasteland, Whitman's self-song in the grass, Roethke's "fragile" "Edenic pastoralism," ${ }^{31}$ and no doubt other intertexts besides suggests a tortuous relationship between the self and nature, a troubled connection to the poetic tradition, and even the old affirmation, across a field of garbage (environmental, cultural, political). By way of the ubiquitous letters " $\mathrm{X}$ " and " $\mathrm{Y}$ " (almost always readable as syntax's x-axis and grammar's y-axis, respectively), the writing and reading of poetry, including the violence of interpretation to the poem's syntactical flow, are also suggested.

To focus briefly on the individual plays, a reading of Terminal Hip may justify Wellman's claim that he was seeking religious meaning, but not in the West. Terminal Hip may owe its "structure" (or vague mimicry of signs that, read together, recall a narrative, perhaps the "ghostly narrative" Wellman mentions ${ }^{32}$ ) to Walt Whitman's "Song of Myself" in Leaves of Grass, a poem structured in turn on the career of Christ. Wellman told David Savran that, in the bad-writing plays, he "wasn't trying to make any sense or tell a story" but that he "found certain patterns emerging. I found a sort of lofty poetic line developing that reminded me of Whitman." ${ }^{33}$ While in the play's conclusion "a panda ghost sinks to the center of the world and sits there and sings," several pages earlier he has recalled the crucifixion (Whitman's "Corpses rise, gashes heal, fastenings roll from me. / I 
troop forth replenish'd with supreme power ..." [969-70]) when he writes:

How he on X feigned Y, hounded the Savior all his days, inspired his Xification, got Him no gumballs, derided him in His final agony, gambled for His garments at the foot of the cross, the whole kit and kaboodle. Philip Botely shows symptoms of X. Philip Boxley has not been vaccinated against hypofluvia.

We see here the appropriation of Christ's passion to "X," which is identified, never more clearly than here, with syntactical "hypofluvia" or flow. Then, back at the beginning of the poem-play, there are lines like "Men like signs. Signs make sense of things" (Whitman's "Or I guess [the grass] is a uniform hieroglyphic" [106]). And moving forward, as does Whitman's speaker ("It is time to explain myself - let us stand up" [1134]): "Gotta move sideways, all balled up like so. . . . Moving sideways to escape detection." And there is, of course, the pervasive hint of betrayal (Whitman's "They have left me helpless to a red marauder" [635]): "Pay off $\mathrm{X}$ in the name of $\mathrm{Y}$, advance career through artful changes." 34

Like that of Terminal Hip, the conclusion of Cellophane also echoes the conclusion of another poem to alert one retrospectively to other quotations and echoes: this time it is T. S. Eliot's "The Love Song of J. Alfred Prufrock" ("We have lingered in the chambers of the sea / By sea-girls wreathed in seaweed red and brown" [129-30]). Wellman writes: "Limos in limo heaven, with little limo wings./Burning limos, in limo holocaust $\mathrm{O}$ aer./Dreaming limos at the bottom of the sea. In the first part, "From Mad Tomatoes," there is a dramatic structure consisting of the speaker, generally identified by the verb form "am"; a "you," which "am" berates and lectures (Prufrock's "Let us go then, you and I" [Line 1]); and the "labernath," which is a powerful liar. "Wow that labernath!" the speaker says, and "Who as has the labernath him do all," but the labernath cannot be trusted: "You go aks at him labernath. / They tell you some crowe. / They tell you some indeed crowe." The labernath may be associated with "at cat," which seems to me to suggest a condition of displacement, dissonance, and alienation, a common condition ("We all was / At cat") which might have been avoided: "it mighta could if we all hadda been / of one mind." Perhaps owing to the labernath and the condition of being at cat, the "Mad Tomatoes" denouement seems to consist of Eliot's dead crossing London Bridge, not in "Prufrock" but in The Waste Land: "The X's. / The Y's. / Came across in and out. / All / At cat like they knew," and the upshot is "Longtime looksee allatime at zero am." Is this the zero-degree of the "affectless" postmodern world? Meanwhile language becomes thematized by the play of binaries. At cat as "not once at dog am," 35 suggesting the Saussurean description of binary signifiers and its legacy in poststructural difference: in contradiction to "at dog," "at cat" forms a signifier; as a singular 
signified, "cat" is distinguished from the pack animal signified by "dog": we are operating on social and linguistic levels, and perhaps others besides, to suggest a condition of - what, anomie? Entropy? Postmodernity? Countercultural failure? The breakdown of the Cold War consensus? The nature of a Language poem? Signs are selected and arranged to evoke questions about patterns of meaning, but these questions go unanswered.

Cellophane's next part, "From Hollowness," continues to gesture toward meanings relating to environmental damage and also to a loss of meaning and spirituality. With respect to the American landscape, this section is filled with scenes of devastation and, in Part 2, it is hard not to associate the polluted river, "Cellophane wrapers all the way to the bank," not only with the Thames of The Waste Land, but also with the Cuyahoga River flowing into Lake Erie through Cleveland ("Heaps of industrial hooha all the way, yeah! To the bank. Yeah!"), Wellman's home town, which was so filled with chemicals that in 1969 it caught fire ("All the same on fire shall have did am. / By the dump all the way to the bank"). Here it is easy to see the slide from effects (dumps, river fires) to causes (industrialization, banks). With respect to the cultural and the political, "labernath" is a highly ambiguous figure, which could refer to the Borgesian labyrinth or the Language poem. "From 'S Sake," the play's third part, suggests that God, the author-god or god-the-subject is missing. However, for the first time in Cellophane, we encounter the word "I," both in reference to Jesus ("I am the way, Jesus said, and the light and the life") and in reference perhaps to the speaker: "I don't know who I am. ... I am thoroughly at sea in the weariness of prolonged political emptiness." This mode is much more confessional and metacritical if we keep our focus on a linguistic relationship between $\mathrm{X}$ and $\mathrm{Y}$ : "[a] well-oiled insoluable conundrum transfixes $\mathrm{X}$ in the name of $\mathrm{Y}$ while down the road some man is trying to find $Y^{\prime}$ in the crowe's eye strange." That is, a personal resolution can be effected by being the man down the road looking for meaning in the crow's eye, here Y-prime or a meaning displaced from the meaning offered by power. Or, on the contrary, the man may encounter the lying "crowe" which turned up earlier in the play. Associated with expression's escape from power, here there may be an affirmation of the syntactical: "For X belongs": "X to Y / X' to somewheres they told of once in error. . . X X upon the uncharted road. / X on the move forever the blue the gasp the." Parts 3 and 4 introduce a "he" and "she" and, by the beginning of Part 5 (right on schedule?), "am" seems to be, or to have become, "Fortune's basket case" 36 - to echo what Megan, in The Bad Infinity, refers to as Romeo and Juliet's "old-hat dead language. ${ }^{\prime 37}$ In other words, there seems to be some struggle involving a man and a woman and perhaps even a crisis. But those outlines appear only erratically, if at all. 


\section{The Paragram and the General Economy}

To the foregoing remarks about Cellophane and Terminal Hip, Bernstein would say that "[t]he obvious problem is that the poem said in any other way is not the poem":

... think only

of the undercurrent of anagrammatical

transformations, the semantic contribution of

the visual representation of the text, the

particular associations evoked by the phonic

configurations. These features are related to the

"nonsemantic" effects that Forrest-Thomson

describes as contributing toward the "total image-complex"

of the poem. ${ }^{38}$

Here Bernstein is describing what Steve McCaffery calls the "paragram" as a form of expression:

For while assignable to a certain order of production [content of expression], value, and meaning [form of content], the paragram [does] not derive necessarily from an intentionality or conscious rhetoricity and seem $[\mathrm{s}]$ an inevitable consequence of writing's alphabetic, combinatory nature. Seen this way as emerging from the multiple ruptures that alphabetic components bring to virtuality, meaning becomes partly the production of a general economy, a persistent excess, nonintentionality, and expenditure without reserve through writing's component letters.

There is no transparency to language and meaning, and the production of meaning, owing to forms of, and even contents of, expression, is always already partly engaged in the production of nonsense, or the flow of the general economy of language. Or again as McCaffery puts it, the paragram is

that aspect of language which escapes all discourse and which commits writing unavoidably to a general economy and to the transphenomenal paradox of an unpresentability that serves as a necessary condition of writing's capacity to present. All of this suggests a constitutional nonpresence in meaning itself. ${ }^{39}$ 
Because the production of meaning is always also the production of elements and effects that are nonmeaningful, there is no meaning that is not also paragrammatic to a certain degree. The Language poets in their texts and performances and Wellman in his plays - the bad-writing plays especially - are merely directing their energies more than usual to the paragrammatic aspect of language and performance.

Again, an interpretive descriptive procedure elides the actual process of reception, reading, and spectatorship. This process is chaotic, at least until the text is brought to order through the exercise of reading strategies. I will suggest that Wellman's lines have an important affinity with Bernstein's poetic practice. McCaffery quotes a 1979 text by Bernstein, which, while less readable than Wellman's text, operates in a similar way:

Ig ak abberflappi. mogh \& hmog ick pug eh nche ebag ot eb v joram lMbrp nly ti asw evn dictcr ot heh ghtr rties. ey Ancded lla tghn heh ugrf het keyon. hnny iKerw. in VazoOn uv spAz ah's ee 'ook up an ays yr bitder guLpIng sum u pulLs. ig jis see kHe nig MiSSy heh d sogA chHooPp \& abhor ih cN gt eGulfer ee mattripg ${ }^{40}$

Perloff tells us that, in Bernstein's business poems, the enemy is the media and all systems of data processing that "suppress 'redundancy' or 'noise" in favor of a totalitarian monologism. Faced with the mechanical binarism and routinization of computer systems, a Language poet like Bernstein will create a linguistic and cultural countercurrent. Perloff writes,

The poetic function, in this scheme of things, subordinates the informational axis (language used as a pure instrument of efficient communication) to what we might call the axis of redundancy, "meanings" now being created by all those elements of reference that go beyond the quantifiable communication of data from A to B. ${ }^{41}$

The informational axis, like the grammatical axis, is subjected, in this kind of Language poetry, to the noise axis, which corresponds to the syntagmatic. In McCaffery's reading of Bernstein's poem, whatever this text tries to mean is accompanied by a great deal of waste that, to the degree that it is not useful or recuperable as meaning, exemplifies the general economy of language. To begin with, this text is sufficiently "English" so that it is not completely separate from a restrictive economy, which is an economy of energy conservation and exchange. With respect to the form of expression, there is, in the materiality of the words 
and word cognates, certain resemblances that loop back to meaningful language forms. Here we recognize the word "abhor" and cognates of other ordinary words, and the more words we recognize the greater our urge to interpret (to form, that is, our own restrictive economies). To do so we would then have to sift through the relentless lexical and typographical anomalies. Starting perhaps with "abhor," meanings would accumulate, perhaps to the point where we might hazard an overall interpretation. The text baits us in our interpretive habit, and much of the interest and even pleasure of the text is registering the suspicious "words" that even suggest a cryptography and a cipher, lexemes like "dictcr" "'ook up," "guLpIng," "MiSSy," and so forth. McCaffery himself focuses on "in VazoOn uv spAz" as " "invasion of space."” 42

But of course McCaffery's point is that meaning's advance and withdrawal prevents "all certainty of meaning." As McCaffery puts it, the text displays

a regulating, conservational disposition that limits and organizes the independent letters, pushing them toward the word as a component in the articulated production and accumulation of meaning, and the other disposition that drives the letters into nonsemantic material ensembles that yield no profit.

Language's dispositions tend in different directions, first toward meaning as a restrictive economy and second toward its nonmeaningful productivity, the general economy, which arises at the very instant it is trying to mean. The lure of interpretation may keep us interested; however, McCaffery's point is that, while lexemes and lexical cognates, or typography, may "mean" at the particle level, the passage does not communicate a message but instead effects overall the "general rematerialization of language." McCaffery writes, for example, that "Capitalization here serves no grammatical purpose but is simply a fortuitous registry of eruption at the meeting of the linguistic sign with its unincorporatable materiality." ${ }^{43}$ That eruption is the appearance in our field of reading and interpreting of that in language writing which is unassimilable, impermeable, but also irrepressible: it is the infusion of the general economy into our own reading practice.

Affectively, what happens is suggested by Bernstein in his description of the poems of Leslie Scalapino:

it is the rhythm created by permutating the attentional beams, the chordal patterns created by her serial scannings, that create the musical coherence that takes the work beyond any distancing or dislocating devices that serve to build it. The refusal to be absorbed in any single focus on a situation gives way to a 
multifocused absorption that eerily shifts, as an ambiguous figure, from anxious to erotic to diffident to hypnotic.

The eerie shifts - ambiguity, anxiety, eroticism, diffidence, hypnosis - are all responses of an affective kind, any one of them too inchoate to describe as an emotion. The goal of Language poetry of this kind is to maintain an affective flight along the border between meaning and the general economy, even as it erodes the border. Bernstein says "the reader stays plugged into the wave-like pulse of the writing. In other words, you keep moving through the writing without having to come up for ideational air; the ideas are all inside the process." 44 As we have seen, Wellman's bad-writing plays demonstrate or feint toward meaning repeatedly and even repeat the same gesture, but meaning is never fully produced. There is the intensity of recognition in the meaning that comes into view, and the intensity of its immediate withdrawal, what Wellman means in referring to the "pulled punch": he writes that "[a]n incomplete action figures forth a shadow, or limb, that completes itself variously - like the flinch response to a pulled punch - in the imaginary space of an audience member's consciousness." ${ }^{45}$ The unkept promise of the incomplete proposition is a residual question or mystery. In this testimony, the incoherence of the signs and the theatrical effects lead to a spectatorly absorption over the course of the performance in the ephemeral impressions made by repetitions and other recognitions over time. Wellman's "pulled punch" describes the gesture in which, in lieu of recognition and understanding, the spectator experiences the affective intensity of meaning denied or deferred and supplanted, in the next instance, by a different feint toward meaning.

Bernstein identifies the affects produced this way as "absorption" and "impermeability": the first, absorption, he writes, is "engrossing, engulfing / completely, engaging, arresting attention, reverie / attention intensification, rhapsodic, spellbinding, / mesmerizing, hypnotic, total, riveting, / enthralling: belief, conviction, silence." The second, impermeability, includes "artifice, boredom, / exaggeration, attention scattering, distraction, / digression, interruptive, transgressive, / undecorous, anticonventional, unintegrated, fractured, / fragmented" and so forth. These affects form, Bernstein says, poetry's "outer limit" and its "inner limit": in other words, they are constraints on poetic response in the relative absence of meaning. In the relative absence of meaning, absorption and impermeability's "intersection," interface, or phase space is, Bernstein says, "flesh," 46 and in this way he suggests that the individual's recourse is to bodily rhythms, with which absorption and impermeability are involved. As limits, these affects form the range of affect's variability over the course of a reading or a spell of spectatorship: they form the bounds of chaos along a line running parallel with the flow of the general economy. In this chaotic system, meaning's emergence and withdrawal can contribute to either absorptive or impermeable effects. Meaning 
is essential as an intensifier so long as its subordination to the nonmeaningful production of affect can be maintained.

McCaffery and Bernstein theorize the affective flow produced by Language poetry in terms of the forms of expression of the general economy of language and the reader's contrasting dispositions toward and away from meaning. The Language poet agitates language with a cascade of meaningless and radioactive expressions that together sustain for a time an affective, rather than meaningful or emotional, intensity. The result is an affective and wasteful flow which develops only when power is prevented from enforcing a relation of nonrelation between expression, on the one hand, and, on the other hand, official discourse, including narratives and generic codes. Meaning forms when expression corresponds transparently with official discourse. Meaning forms when, owing to this transparency, an enunciation, always a pragmatic singularity, is made through repetition to appear to transcend its moment to take the form of truth. Language poetry reverses this process by denying expression its transparency, by supplanting repetition and the illusion of transcendence with variation in a series of enunciations, each a singular occasion for the contrastive dispositions toward and away from meaning with absorptive and alienating effects. These dispositions produce a flow of affect, owing to the recurrent pulled punch of meaning, which erodes the border between the general and restrictive economies.

\section{Writing to the General Economy and Writing to Rule}

This interplay between the general economy and a restrictive economy is the theoretical basis for a nonmetaphorical description of chaos writing offered by McCaffery and assented to by Bernstein. But what is gained, then, by identifying Language writing with a nonlinear complex system? Bernstein is - and is not"suggesting that poetics, or poetry, is a chaotic system." He writes that poetry is produced by, and complexly related to, a chaotic system. Poetry "charts the turbulent phenomenon known as human being, must reflect this in the nonperiodic flow of its 'chaotic' prosody." Poetry, "in its most ecstatic manifestation," is indeed a chaotic or "nonlinear dynamic system." As a chaotic system, poetry is "constrained ... controllable not in its flowering but in the progression toward chaos or move backward out of it: perhaps this is the narrative of a poem that poetics can address. ${ }^{\prime 47}$ At most, Bernstein suggests that a chaotic prosody is set going by a combination of aesthetic and referential features, but its "flowering" is beyond apprehension, to say nothing of analysis. What actually goes on in the consciousness of a reader or spectator, once he or she has reached the "flinch" plateau under the incessant impact of pulled punches, is unknown.

If this affective flight of language is unknowable, this fact would have important implications for understanding the relationship of chaos theory to a reading of Wellman's plays. At the moment when he turns to chaos theory, 
Wellman writes of the plays' "fractal" nature. ${ }^{48}$ In terms of the affective process just described,

1) the (always singular) enunciation, "radioactive" with meaning, is affectively intense more than it is meaningful;

2) owing to the chaos of the meanings of the enunciation, the whole ideological order (form of content) is not repeated. What is repeatable, with variation, is the degree of chaos;

3 ) the repetition of a degree of chaos (the fractal) $)^{49}$ is always the repetition of the constraints on the singular enunciation, which include the form of content (the ideological order) and the contents of expression (rhetoric, grammar, body, voice, gesture, theatrical production, institutionality) imposed upon the enunciation.

Expression is the most variable, while in each new enunciation, the same constraints are operative: the fractal degree of chaos, with some variation from enunciation to enunciation, is maintained. This degree of chaos, registered as affective intensity, is the degree of openness in the relation of nonrelation between expression and content. There is no way to measure this degree, except, perhaps, by wiring spectators to medical equipment to arrive at some kind of somatic signature. We infer from science that this degree of chaos, whatever it is, is selfsimilar from enunciation to enunciation, and from scale to scale, beginning with the (corrupted) lexeme and continuing to include the play itself. That the degree of chaos, as an aspect of reception, is unmeasurable is certainly suggested when Hayles herself makes no attempt to measure it. Hayles stresses the importance of "recursive symmetries" 50 and the manner in which constraints feed back into each step in the writing and reading processes. She writes of the fundamental importance of ethics in the opening or closing of the writing procedure. ${ }^{51}$ Yet she never goes further in her description of chaos than to say that the text, in a given phase, is or is not complex.

I have suggested that the Language poets, and Wellman in Cellophane and Terminal Hip, exploit the gap between expression and content to give materiality back to expression and to resist the suppression of expression in the service of meaning and power. The reader's and spectator's dispositions toward and away from meaning maintain an affective intensity. There is, in fact, no part of this model that is knowable except the features of the text or performance, although, as has been noted, Bernstein feels that poetics can describe in general the way that chaos in poetry comes into being. Wellman writes to the general economy in his bad-writing plays of the late 1980s and early 1990s: Cellophane, Terminal Hip, and to a great degree in Three Americanisms. He writes to rule in plays such as Cat's Paw (1995). 
A well-known example of writing to rule is offered by Perloff in Radical Artifice (1991), in which she discusses performances of John Cage's Lecture on the Weather, once in 1984 in California and again in 1989 in Maryland. Perloff discusses both Cage's procedure and her observation of the audience's unconscious, somatic group response to the inclement "weather" to which Cage subjected it. Perloff, in ways implicitly unacceptable to McCaffery and Bernstein, suggests that the effects she describes were caused by the operation of Cage's procedure. His goal, according to Perloff, was to bypass the law in the name of "discovery" because, as he says, "Of all professions the law is the least concerned with aspiration. It is concerned with precedent, not with discovery." Using a "strictly planned mathematical system," Cage extracts passages from the writings of Henry David Thoreau. Cage desires to use Thoreau's writings, in Perloff's words, to "[pay] homage to the qualities of American ingenuity, pragmatism, and good sense epitomized for Cage in the person of Thoreau" while avoiding the law ("precedent") in the form of meaning. By employing a mathematical system for selecting texts from Thoreau, except for selecting the archive on which this system operates to begin with, Cage effaces himself and confounds the law's operation through him, in the form of interpretation, aesthetic response, and so forth. As Perloff explains, the fixed rule of this mathematical system helped Cage to evade himself as a human system so that Thoreau's language could be offered to an assembly of other people with diminished mediation. Perloff writes that the performance of Lecture on the Weather "functions as a 'strange attractor' or "unpredictable system"” so that, she continues, "[t] he performance . . . is not about [does not represent] the weather; it is weather." Perloff writes, "the 'lecture' on the weather turns the simulated event into a real one, causing the audience to take shelter from the cruel elements." In California, she says, the audience, arranged in some disorder in the space, responded to the storm in an interesting way. She reports that "[b]y the time the storm 'broke,' lightning flashes appearing on the large screen in the form of briefly projected negatives of drawings by Thoreau, the audience had become something of a football huddle. Everyone wanted to join together to get out of the storm." ${ }^{52}$ Here the question is not so much the audience's behavior, but how much a mathematical procedure had to do with it. Certainly Cage, in Perloff's account, took every measure, within the rules he made, to eliminate himself from the equation as a subject, and Perloff describes the audience less as subjects, than as a statistical mass - a "huddle." Yet the causal connection between Cage's procedure and the group response to ordinary stimuli remains vague and probably insupportable. After all, the mathematical procedure used in arranging Thoreau's writings cannot determine how spectators process Thoreau's language in its radioactivity. McCaffery takes issue with the tendency of a rule, as a writing procedure, to maintain the author-subject as author of the 
rule and agent of its implementation. Of Ron Silliman's similarly procedural poem Ketjak, McCaffery writes,

What is striking . . . is the work's double orientation toward, on the one hand, a textual production through a "random" economy or a free play of signification ... and on the other hand an accumulative, preservational movement committed to the noncontamination of a transcendental "procedure" that seems precisely modeled on the Hegelian aufhebung [sublation, transcendence, or synthesis] and permits the structure to foreground itself as a first-order attention.

There is in the authorship, in other words, no erosion of the borders between the general economy and the procedure, which, as a transcendent fabrication, in theory would not really achieve the subject's effacement or dissolution of self-consciousness. In other words, from the standpoint of authorship, it is a restrictive economy, one that does not deliver the consciousness of the spectator to the affective nonmeaning of the general economy. A page earlier, McCaffery writes that "[c]rucial in Hegel's argument is the inviolable, irreducible status of self-consciousness itself. Transgression and the negative in the Hegelian system do not risk the loss of the subject." Regarding Cage, McCaffery groups him with Silliman, noting that "[ $\mathrm{t}]$ his Hegelian aspect applies to most instances of procedural writing. ${ }^{.53}$ It is suggested, then, that the encounter between the general economy and a mathematically sustained, "Hegelian" restrictive economy does not risk the subject as author in the writing. If Cage's Lecture on the Weather did indeed, through the performance's absorptive and impermeable effects, risk the subjectivity of the spectator, the mathematical procedure or rule may have operated for Cage mostly as an especially disciplined form of bad writing.

Nor is the subject, either of author or spectator, at risk in Wellman's Cat's Paw: A Meditation on the Don Juan Theme. ${ }^{54}$ Begun in 1995 and first staged in 2000, Cat's Paw is written according to rule even as it produces self-similarity as a metaphor. Like Tom Stoppard's Arcadia (1993), the playwright's intentions are clearly heuristic, so that, where chaos is concerned, the play serves more as a model of certain chaotic principles than, like the bad-writing plays, as an actual means of producing chaos. Arcadia was, Demastes tells us, "the first mainstream theatre product consciously designed to be a "chaos' play." Stoppard's play is said to be arranged on the principle of fractal self-similarity, which means that the same fractal shape or formula occurs on different scales. Plays written on this principle are thought to be formally nonlinear to suggest the chaotic lives and feelings of individual persons. Concerning Arcadia, Demastes writes, "In the play, we have instances of self-similar repetition between 1809 and 1993, between 
leaf and park, between the formation of Thomasina's leaf and Bernard's Byron story, between Septimus's hermit project and Valentine's computer calculations." That is, the parallels are apparently significant. Demastes continues: "[e]ven the algorithmic graphing of the leaf (the smallest-scale system in the play) finds selfsimilar parallels in the very nonlinear, seemingly chaotic structure of the play (the largest scale system). ${ }^{" 55}$ But for all the talk of mathematics, Demastes is correct to point to the metaphoricity of this kind of play. Dramaturgically, such a chaos play seems to involve fashioning parallels for the mind, the principal excitement being in contemplating this new chaos paradigm.

Wellman's Cat's Paw is also a meditation on fractal self-similarity and, while Wellman more or less follows a rule he has made for himself, the play is one of the more realistic and linear plays in his oeuvre. Although this is a Don Juan play, Wellman's self-imposed rule is that no men will appear in the play and that the women will not discuss men in the play. Men, especially as agents of abuse of women, are a present absence, introduced most apparently through references to experiences so traumatic for the women (occurring in Bermuda, Caracas, and Singapore), that they are the last thing the women wish to talk about. The parallels between traumas and the vertical, gravity-prone settings in which these scenes take place (the observation decks of the Empire State Building and of the World Trade Center; the fist of the Statue of Liberty, where Jo takes her daughter Lindsey by evading the guards; and the hallway of the court building during a hearing on Jo's trespass the scene before) provide a linear restaging of similar conflicts among characters. Lindsey, too young to have had her Don Juan event, is brimming with Young Republican aspiration, while the adult women, systemically complicated by their Don Juan events, range in dispositional polarity from the paranoid Jane to her ex-hippy mother, who embraced her Don Juan moment in a conscious pursuit of depravity. "Depravity," she says, "was my object." 56 Jane's mother is sufficiently self-aware to observe that she is herself "unself-similar" 57 and thus unlike her self-similar daughter, who wears men's clothes and who, ironically, seems much more constrained in her artsy New York City milieu than her mother is in Iowa. Jane's mother says, "I feel rich and full and large with hopefulness, blood, and a sense of true being." Even in her depravity she was, she says, "true to my nature, and to the clothes I wore." 58 The suggestion seems to be, not that Jane's mother is free from constraint, but that her fractal evolution (variation in repetition) has been different from that of anyone else in the play, which makes her in that dramatic context capable of radically troubling her daughter and the worldview with which she is associated. Again, the play presents chaos mostly as a metaphor, the no-man rule notwithstanding.

\section{Conclusion: Back to the Theatre}

More relentlessly than Cat's Paw and many other plays, Cellophane and 
Terminal Hip constrain the body by greatly reducing extra linguistic theatrical potential in order to exploit the radioactivity of language. These plays were part of another Wellman experiment. If Wellman may have been in some sense a Language poet all along, the bad-writing experiment brought the poet fully out of the closet. He chose not to take this particular form very far. I have tried here to describe the nonmeaningful exploitation of the radioactivity of language, and, provisionally, its production of an affective state of intensity. Of course the style can be frustrating to those insistent on meaning. "When Terminal Hip appeared in 1992, a Los Angeles Times reviewer concluded, "it may be hip, but why bother and who cares?" ${ }^{59}$ Yet eight years later, a second Los Angeles reviewer wrote that there "emerges [a] different kind of sense ... if you concede the all-but-futile battle of trying the parse [the] monologue for linear semantic content, and instead let Wellman's recurring imagery and the carefully crafted mood shifts in James Martin's staging guide the experience. ${ }^{160}$ They know that they often must preach to the converted. McCaffery writes that "THE TEXTUAL INTENTION PRESUPPOSES READERS WHO KNOW THE LANGUAGE CONSPIRACY IN OPERATION." ${ }^{61}$ This raises important questions about the institutional constraints on artistic power. The butterfly effect of avant-gardism has yet to be conclusively established. Meanwhile, I hope I have shown that in the 1990s the Language poets inhabited the same discursive formation as deconstruction and chaos theory, two isomorphic systems. All three were in some sense radioactive, i.e., complex mutual intensifiers, especially for those who needed to appropriate them to imagine an escape from the postmodern. The radioactive or theoretical relation of nonrelation characterizing this discursive (or antidiscursive) formation of expression (Language poetry, deconstruction, chaos theory) engaged with postmodern forms of content to express the impulse to escape. This escape entailed no physical relocation but productive engagement (if that were possible) with the bad infinity of reified postmodern culture. Bernstein's "poetics" tells us that Language poetry, in the end, exists "to provoke response and to evoke company." ${ }^{\prime 2}$ The modesty of the Language poets' claims is striking, as is the note of piety, because nothing is guaranteed. Meanwhile, Wellman's theatre remains, in its affective intensity, a "theatre of wonders."

\section{Notes}

1. Marjorie Perloff, Foreword, Cellophane: Plays by Mac Wellman (Baltimore: PAJ, 2001) xi.

2. The register of Bernstein's papers, 1962-2000, at the University of California, San Diego (Mandeville Special Collections Lib., Geisel Lib., mss. 0519, 10 Sept. $2009<$ http://orpheus.ucsd. edu/speccoll/testing $/ \mathrm{html} / \mathrm{mss} 0519 \mathrm{a} . \mathrm{html}>$ ) indicates that the archive contains correspondence from Wellman between 1977 and 1993, as well as his unpublished paper submitted for the $L=A=N=G=U=A=G=E$ Book.

3. Mel Gussow writes that "Language is reaffirming itself in the American theatre, and the harbingers are Mac Wellman, Eric Overmyer and David Ives. In a reaction against the recent emphasis 
on performance art, they value words - the polysyllabic as well as colorful vernacular. In common, their dialogue has an imaginative intellectual base. By intention, these plays begin with a rational impulse, seem to be written intuitively and generally end at recognizable destinations, but the journey can be outrageous - a trip to a Xanadu of the mind" ("Playwrights Who Put Words at Center Stage," New York Times 11 Feb 1990: H:5).

4. Helen Shaw, "Foreword: Mac Wellman and Things of the Devil," The Difficulty of Crossing a Field: Nine New Plays by Mac Wellman (Minneapolis: U of Minnesota P, 2008) vii-xii.

5. George Hartley, Textual Politics and the Language Poets (Bloomington: Indiana U P, 1989) 6.

6. Charles Bernstein, A Poetics (Cambridge, MA: Harvard U P, 1992) 92, emphasis in original.

7. Steve McCaffery, in "Writing as a General Economy," Artifice and Indeterminacy: An Anthology of New Poetics, ed. Christopher Beach (Tuscaloosa: U of Alabama P, 1998), quotes Bataille's definition of a general economy as that which "'makes apparent that excesses of energy are produced [that] can only be lost without the slightest aim, consequently without meaning" (201). With regard to Hjelmslev, McCaffery writes that he "is one of several contemporary linguists who distinguish language as a system from its material support in sound and ink. . . As its material support, sound and ink are separable from the signifying process, but at the same time the process is unsupportable without it. In light of this one could consider language's materiality as meaning's heterological object, as that area inevitably involved within the semantic apparatus that meaning casts out and rejects" (203).

8. Hartley writes that Language writing stems from "the rejection of the dominant model for poetic production and reception today [1989]-the so-called voice poem[, which] depends on a model of communication that needs to be challenged: the notion that the poet (a self-present subject) transmits a particular message ('experience,' 'emotion') to a reader (another self-present subject) through a language which is neutral, transparent, "natural'" (xii).

9. Bernstein 3.

10. Hartley 96.

11. Mac Wellman, "The Theatre of Good Intentions," Performing Arts Journal 13.3 (1984): 59.

12. Brian Massumi, in "The Autonomy of Affect," Cultural Critique 31 (Fall 1995), explains the missing half-second: "Experiments were performed on patients who had been implanted with cortical electrodes for medical purposes. Mild electrical pulses were administered to the electrode and also to points on the skin. In either case, the stimulation was felt only if it lasted more than half a second: a half a second, the minimum perceivable lapse. If the cortical electrode was fired a half-second before the skin was stimulated, patients reported feeling the skin pulse first. The research speculated that sensation involves a 'backward referral in time'-in other words, that sensation is organized recursively before being linearized, before it is redirected outwardly to take its part in a conscious chain of actions and reactions. Brain and skin form a resonating vessel. Stimulation turns inward, is folded into the body, except that there is no inside for it to be in, because the body is radically open, absorbing impulses quicker than they can be perceived, and because the entire vibratory event is unconscious, out of mind. Its anomaly is smoothed over retrospectively to fit conscious requirements of continuity and linear causality" (89). He continues that "the half-second is missed not because it is empty, but because it is overfull.... Will and consciousness are subtractive" (90, emphasis in original).

13. N. Katherine Hayles, Chaos Bound: Orderly Disorder in Contemporary Literature and Science (Ithaca: Cornell U P, 1990) 176.

14. Wellman not only borrows terms and concepts from Gleick in writing Three Americanisms, but his epigraph to the play quotes from Gleick, Cellophane: Plays by Mac Wellman (Baltimore: Johns Hopkins U P, 2001) 186. Meanwhile, Tom Stoppard acknowledges his debt to Gleick in writing Arcadia in an interview with Mel Gussow (American Theatre [Dec. 1995]: 25). Stoppard said, "I thought that quantum mechanics and chaos mathematics suggested themselves as quite interesting and powerful metaphors for human behavior."

15. Hayles 184.

16. William W. Demastes, Theatre of Chaos: Beyond Absurdism, into Orderly Disorder (Cambridge: Cambridge U P, 1998) 10.

17. Marjorie Perloff, The Poetics of Indeterminacy: Rimbaud to Cage (Princeton: Princeton U P, 1981) 75 . 
18. Hartley 72 .

19. Marjorie Perloff, Radical Artifice: Writing Poetry in the Age of Media, new ed. (Chicago: U of Chicago P, 1994) 197.

20. Bernstein 2, 1 .

21. Interview with Shawn-Marie Garrett, Theater 27.2-3 (1997): 91.

22. Mac Wellman, Cellophane: Plays by Mac Wellman (Baltimore: Johns Hopkins U P, 2001) 60.

23. Mac Wellman, "Poisonous Tomatoes: A Statement on Logic and the Theater," The Bad Infinity: Eight Plays (Baltimore: Johns Hopkins U P, 1994) ix.

24. Wellman, "The Theatre of Good Intentions" 66, 65..

25. Eric Overmyer explains the bad infinity as "a flawed system, which replicates itself forever" (“Mac Wellman's Horizontal Avalanches," Theater 21.3 [1990]: 55-56). Wellman, Overmyer writes,

explores a number of such systems: geopolitics, fashion, economics, international banking, crime, criticism, media, language, and the theatre itself, or rather, the conventions of the conventional theatre. A Bad Infinity if ever there was one. (56)

And yet, Overmyer also says

I find Wellman's work occasionally frustrating, as if he is pursuing an ideology of obfuscation, a strategy of deliberate inaccessibility in order to escape the received ideas of the theatre. But when I connect with his work, I understand it as I understand poetry, on a deep, cellular level. Much in life is unexplained, unexplainable, mysterious. So are Wellman's plays. (56)

In Overmyer's discussion we see an odd tension between his philosophical explanation of Hegel's phrase and his critical and affective responses to Wellman's work. If a bad infinity has no productive engagement with anything but itself, wouldn't the journey into the mysterious and unexplainable (operating on a deep cellular level) lead away from the flawed conventions operating in the bad infinities Overmyer identifies? Mightn't it lead to a fuller engagement with history?

26. Bernstein describes a "strategy of tactics" with which "to think through ... the relation among formal, antiaccommodationist, group-identified, cultural, regional, and gender-based poetic tactics so that they form a complementarity of critiques, projected onto an imaginary social whole in the manner of a negative dialectics" (164). Negative dialectics is Adorno's response, Hartley writes, to his understanding that, owing to commodification and reification in modern life, "there is no positive Aufhebung [Hegel's synthesis, sublation, or transcendence] of the dialectic" (58). In place of Absolute Spirit's teleological unfolding through Spirit's engagement with necessity, there is a bad infinity in which opposing objects remain in antagonistic juxtaposition because each object is itself self-contradictory. Each object has been set loose, by reification, from its referent in History to become a signifier/signified and has no absolute positivity with which to engage its other. Poetic tactics can foreground these contradictions or aporias with meaningful and nonmeaningful effect. The "imaginary social whole" Bernstein mentions is a projection that results from innumerable poetic encounters. If one can imagine it, there is a negative whole or totality that stands in opposition to its positive counterpart.

27. Quoted in Hartley (58).

28. Hartley 77.

29. Wellman, Cellophane 151.

30. Mac Wellman, Terminal Hip, The Bad Infinity: Eight Plays (Baltimore: Johns Hopkins U P, 1994) 263.

31. Cary Nelson, Our Last First Poets: Vision and History in Contemporary American Poetry (Urbana: U of Illinois P, 1982) 47.

32. Wellman, Cellophane 152.

33. Personal Interview with David Savran, American Theatre (Feb. 1999): 19.

34. Terminal Hip 277, 270, 259, 267, 269. 
35. Cellophane 184, 159, 156, 153, 158, 159, 154.

36. Cellphane, 160, 161, 168, 169, 166, 170, 157.

37. Wellman, The Bad Infinity 72.

38. Bernstein 16, 11.

39. McCaffery 206, emphasis in original.

40. Qtd. in McCaffery, "Writing as a General Economy" 211, emphasis added.

41. Perloff, Radical Artifice 187.

42. McCaffery, "Writing as a General Economy" 211-12.

43. 210-12.

44. Bernstein 81, 60 .

45. Mac Wellman, "A Chrestomathy of 22 Answers to 22 Wholly Unaskable and Unrelated Questions Concerning Political and Poetic Theater," Theater (Mar./Apr. 1993): 43.

46. Bernstein 29-30, 66, 86 .

47. 167.

48. Interview with Shawn-Marie Garrett 88.

49. N. Katherine Hayles writes that "[a]n important difference between fractal and Euclidean geometry is the scale-dependent symmetries of fractal norms" (165). Hayles further explains that "[s] caling, as Mandelbrot uses the term, does not imply that the form is the same for scales of different lengths, only that the degree of "irregularity and/or fragmentation is identical at all scales"" (166).

50. 13 .

51. In Hayles's discussion of the novels of Stanislaw Lem she explains "his belief that literature must be about something other than textuality if it is to engage ethical questions" (121). Yet ethics as reference to the things of the world and adjudicating right and wrong would seem to be a second-order operation. The first-order operation is to create a space for writing by establishing a dialectic between "chance"-Hayles's equivalent of the form of expression-and necessity, understood as referential "resistances" (121) to expression. This is "a dialectic that ceaselessly renews itself, wresting rational explanations from the enigmatic silence of the text even as it opens fissures within the text which subvert those explanations" (120).

52. Perloff, Radical Artifice 22-27.

53. McCaffery 209, 208, 209.

54. Mac Wellman, Cat's Paw: A Mediation on the Don Juan Theme, Cellophane: Plays by Mac Wellman (Baltimore: Johns Hopkins U P, 2001) 337.

55. Demastes 85, 102.

56. Wellman, Cat's Paw 353.

57. 349. In the three-play sequence of the bad-writing plays, Three Americans is, as I suggested at the beginning, a transitional play in that it mostly retains the chaotic aspects of Cellophane and Terminal Hip while incorporating a new discourse of chaos theory and a gesture perhaps toward metaphorical self-similarity, suggested, as in the later play Cat's Paw, by way of clothes. Three Americanisms, three poems pulled together in 1993 into one performance with three monologues, opposes the body to clothing, and, just as Jane's mother tells her she should be ashamed of her clothes, it is the clothing of Second Man and First Woman of which they are ashamed. First Man is not ashamed of his clothes, perhaps because he is too chaotically preoccupied with staying alive. First Man, "A strange man," citing fractal pattern and fractal properties, says, "I am caught forever on a Sierpinski carpet in a region infinitely sparse, infinitely many." "The pointed hat," he says, "is my American destiny." Knowing what to do, he runs, he says, "as fast I can, with all my stuff in a red bandanna." Second Man, "a bit more well-heeled," is also less frantic and more apologetic: "I put on someone's clothes not mine. / The clothes cling to my human nakedness. I am ashamed." He has been complicit, he seems to be saying (referring again to Whitman), with the fact that "Grasses grow up and while away unexamined"; and, because America refuses to "approve the cut part" of the U.S. Constitution "about dancing-drunk-in the forest at night, howling before strange gods, all before sun-up, in strange hats, aglow?" he proclaims (Romeo and Juliet again) "A pox on all your houses, you." Second Man is succeeded by First Woman, dressed in "dark clothes, perhaps in mourning," who speaks of keeping one's head down owing to a "wall of flying debris." In contrast to her clothes and her dim view of Second Man, she says, "Being happy is my secret weapon in the war of all against all." 
Echoing, or prefiguring, Jesus H. Christ, the young African American woman in Sincerity Forever, she makes statements like "If the shoe fits, there's something radically wrong with you, you loathsome, misnormal dickhead." Yet her "feminist" spleen, too, resolves itself into the confession that the clothes she wears are not hers, and she is "ashamed" of this ideological betrayal of her "human nakedness" (Three Americanisms 187-205).

58. Wellman, Cat's Paw 349, 353.

59. Philip Brandes, "Language Unravels in 'Terminal Hip,"” Los Angeles Times 10 Nov. 2000: F26.

60. Nancy Churnin, "It May Be Hip But Why Bother and Who Cares," Los Angeles Times 15 June 1992: F1.

61. Qtd. in Bernstein 64.

62164.

63. The phrase "theatre of wonders" belongs to a collection of plays, Theatre of Wonders: Six Contemporary American Plays, edited by Wellman, which appeared from Sun and Moon Press (Los Angeles) in 1985. The collection contained plays by Len Jenkin, Jeffrey Jones, Des McAnuff, Elizabeth Wray, and Mac Wellman. 